\title{
Reliability analysis of a robotic system using hybridized technique
}

\author{
Naveen $\operatorname{Kumar}^{1}$ (D) $\mathrm{Komal}^{2} \cdot$ J. S. Lather ${ }^{3}$
}

Received: 17 February 2017/ Accepted: 13 September 2017/Published online: 22 September 2017

(C) The Author(s) 2017. This article is an open access publication

\begin{abstract}
In this manuscript, the reliability of a robotic system has been analyzed using the available data (containing vagueness, uncertainty, etc). Quantification of involved uncertainties is done through data fuzzification using triangular fuzzy numbers with known spreads as suggested by system experts. With fuzzified data, if the existing fuzzy lambda-tau (FLT) technique is employed, then the computed reliability parameters have wide range of predictions. Therefore, decision-maker cannot suggest any specific and influential managerial strategy to prevent unexpected failures and consequently to improve complex system performance. To overcome this problem, the present study utilizes a hybridized technique. With this technique, fuzzy set theory is utilized to quantify uncertainties, fault tree is utilized for the system modeling, lambda-tau method is utilized to formulate mathematical expressions for failure/repair rates of the system, and genetic algorithm is utilized to solve established nonlinear programming problem. Different reliability parameters of a robotic system are computed and the results are compared with the existing technique. The components of the robotic system follow exponential distribution, i.e., constant. Sensitivity analysis is also performed and impact on system mean time
\end{abstract}

Naveen Kumar

navindma@gmail.com

1 Department of Mathematics, National Institute of Technology (NIT) Kurukshetra, Kurukshetra, Haryana 136119, India

2 Department of Mathematics, Doon University, Dehradun, Uttrakhand, India

3 Department of Electrical Engineering, National Institute of Technology (NIT) Kurukshetra, Kurukshetra, Haryana 136119, India between failures (MTBF) is addressed by varying other reliability parameters. Based on analysis some influential suggestions are given to improve the system performance.

Keywords Reliability analysis - Robotic system · Nonlinear programming - Fuzzy lambda-tau technique

$\begin{array}{ll}\text { Abbreviatons } & \\ \tilde{P} & \text { Fuzzy set } \tilde{P} \\ n & \text { Number of components } \\ & \text { in the system } \\ t & \text { Time } t \\ \lambda_{i} & \text { System } i \text { th component } \\ & \text { failure rate } \\ \tau_{i} & \text { System } i \text { th component } \\ & \text { repair time } \\ \lambda_{s} & \text { System failure rate } \\ \tau_{s} & \text { System repair time } \\ \tilde{P}\left(\lambda_{1}, \lambda_{2}, \ldots, \lambda_{n}, \tau_{1}, \tau_{2}, \ldots, \tau_{n}\right) & \text { Time-independent fuzzy } \\ & \text { reliability index } \\ \tilde{P}\left(t / \lambda_{1}, \lambda_{2}, \ldots, \lambda_{n}, \tau_{1}, \tau_{2}, \ldots, \tau_{n}\right) & \text { Time-dependent fuzzy } \\ & \text { reliability index } \\ \alpha & \text { Alpha-cut } \\ P_{\min } & \text { Minimum value of } \\ P_{\max } & \text { function } P \\ x & \text { Maximum value of } \\ V_{\lambda_{i}}(x) & \text { function } P \\ V_{\tau_{i}}(x) & \text { Generic element } \\ \mathrm{A}_{\mathrm{s}}(\mathrm{t}) & \text { Membership value of } x \\ & \text { in fuzzy set } \tilde{\lambda}_{i} \\ & \text { Membership value of } x \\ & \text { in fuzzy set } \tilde{\tau}_{i} \\ & \text { System availability at } \\ & \text { time } t \\ & \end{array}$




$\begin{array}{ll}\mathrm{R}_{\mathrm{s}}(\mathrm{t}) & \begin{array}{l}\text { System reliability at } \\ \text { time } t\end{array} \\ M_{i} & \begin{array}{l}\text { ith motor as system } \\ \text { component } \\ S_{i}\end{array} \\ \mathrm{Br} & \begin{array}{l}\text { ith sensor as system } \\ \text { component }\end{array} \\ & \text { Bearing as system } \\ & \text { component } \\ \mathrm{Rl} & \text { Roller as system } \\ & \text { component } \\ P c & \text { Probability of crossover } \\ P m & \text { Probability of mutation } \\ l & \text { Bit length }\end{array}$

\section{Acronyms}

FLT Fuzzy lambda-tau

FTA Fault tree analysis

GAs Genetic algorithms

NSGA Nondominated sorting genetic algorithm

MTBF Mean time between failures

ENOF Expected number of failures

\section{Introduction}

Industrial systems usually have complex structures, and thus, the analysis and optimization of their performance require adequate knowledge of human operators and system information for achieving desired industrial goals. To achieve desired industrial goals, a robotic system is widely being used, and therefore, the importance of the robot reliability and quality has been increased. The study of robot reliability is very complex, since a lot of interlocking variables are involved in evaluation of various reliability levels of these systems (Sharma et al. 2010). The research on robotic systems is reported very large in the literature; however, limited work has been reported on reliability of robotic systems (Leuschen et al. 1998; Carreras et al. 1999; Carlson and Murphy 2003; Sharma et al. 2008; Kumar et al. 2012. Specifically, Khodabandehloo (1996) used fault tree for the safety and reliability analysis of robotic system. To improve the safety and reliability of robot manipulator, (Walker and Cavallero 1996a; Walker and
Cavallaro 1996b) used fault tree analysis(FTA) during design phase of the manipulator. Dhillon and Yang (1996) analyze safety and reliability of robotic systems using supplementary variable and Markov techniques, while Carreras et al. (1999) and later on Carreras and Walker (2000) applied interval method for the same purpose. Leuschen et al. (2001) developed a novel fuzzy Markov modeling approach for analyzing fault tolerant of a robot designed for hazardous waste removal. Stancliff et al. (2006) presented a quantitative method for mission reliability estimation of various mobile robots working as teams. The reliability of mechanical robots was improved by Korayem and Iravani (2008) using failure mode analysis and function deployment approach.

From the literature, one can observe that approaches discussed so far for reliability analysis use probabilistic assumptions and crisp historical data which is in general limited and contains vagueness, uncertainty, etc. Practically, for system reliability analysis, constant failure rate model is being utilized, because most of the technical systems show this type of behavior, having some kind of uncertainties (Das 2008; Knezevic and Odoom 2001). Unfortunately, crisp historical data are not sufficient to account for the available uncertainties. Using vague, limited and imprecise data and information about any system such as a robotic system modeling analysis and optimization of the system's overall performance are very difficult. Thus, the issue of robot reliability is related to uncertainty, and in lack of proper knowledge, it is difficult to analyze and predict its behavior. In addition, a system analyst is unable to suggest any necessary action to optimize the performance of a robotic system by enhancing its reliability. Fuzzy sets as suggested by many researchers are used to account for the uncertainties involved in the available information, i.e., in the extracted data (Chen 1994; Cai 1996; Bai and Asgarpoor 1996). In view of above limitations and the applicability of fuzzy set theory for quantifying involved uncertainties, Sharma et al. (2008) analyzed the performance of a complex robotic system using fuzzy lambda-tau(FLT) methodology. In FLT, traditional lambda-tau method (Mishra 1992) is coupled with fuzzy set theory and $\alpha$-cut interval arithmetic operations to analyze fuzzy reliability of any repairable system, and has

Table 1 Basic expressions of lambda-tau methodology

\begin{tabular}{|c|c|c|c|c|}
\hline Gate $\rightarrow$ & $\lambda_{\mathrm{AND}}$ & $\tau_{\mathrm{AND}}$ & $\lambda_{\mathrm{OR}}$ & $\tau_{\mathrm{OR}}$ \\
\hline Expressions & $\prod_{j=1}^{n} \lambda_{j}\left[\sum_{\substack{j=1 \\
j=1 \\
i \neq j}}^{n} \tau_{j}\right]$ & $\frac{\prod_{i=1}^{n} \tau_{i}}{\sum_{j=1}^{n}\left[\begin{array}{c}\prod_{i=1}^{n} \tau_{i} \\
i \neq j\end{array}\right]}$ & $\sum_{i=1}^{n} \lambda_{i}$ & $\frac{\sum_{i=1}^{n} \lambda_{i} \tau_{i}}{\sum_{i=1}^{n} \lambda_{i}}$ \\
\hline
\end{tabular}


Table 2 Some reliability indices for repairable system with constant repair rate model

Table 3 Basic operations on fuzzy numbers

\begin{tabular}{ll}
\hline Reliability indices & Expressions \\
\hline Mean time to failure & MTTF $_{\mathrm{s}}=\frac{1}{\lambda_{\mathrm{s}}}$ \\
Mean time to repair & MTTR $_{\mathrm{s}}=\frac{1}{\mu_{\mathrm{s}}}=\tau_{\mathrm{s}}$ \\
Mean time between failures & $\mathrm{MTBF}_{\mathrm{s}}=\mathrm{MTTF}_{\mathrm{s}}+\mathrm{MTTR}_{\mathrm{s}}$ \\
Expected Number of Failures & $\operatorname{ENOF}_{\mathrm{s}}(0, \mathrm{t})=\frac{\lambda_{\mathrm{s}} \mu_{\mathrm{s}} \mathrm{t}}{\lambda_{\mathrm{s}}+\mu_{\mathrm{s}}}+\frac{\lambda_{\mathrm{s}}^{2}}{\left(\lambda_{\mathrm{s}}+\mu_{\mathrm{s}}\right)^{2}}\left[1-\mathrm{e}^{-\left(\lambda_{\mathrm{s}}+\mu_{\mathrm{s}}\right) \mathrm{t}}\right]$ \\
Availability & $\mathrm{A}_{\mathrm{s}}(\mathrm{t})=\frac{\mu_{\mathrm{s}}}{\lambda_{\mathrm{s}}+\mu_{\mathrm{s}}}+\frac{\lambda_{\mathrm{s}}}{\lambda_{\mathrm{s}}+\mu_{\mathrm{s}}} \mathrm{e}^{-\left(\lambda_{\mathrm{s}}+\mu_{\mathrm{s}}\right) \mathrm{t}}$ \\
Reliability & $\mathrm{R}_{\mathrm{s}}(\mathrm{t})=\mathrm{e}^{-\lambda_{\mathrm{s}} \mathrm{t}}$ \\
\hline
\end{tabular}

\begin{tabular}{lll}
\hline Operation & Crisp & Fuzzy \\
\hline Addition & $A+B$ & $\tilde{A}+\tilde{B}=\left[a_{1}^{(\alpha)}+b_{1}^{(\alpha)}, a_{3}^{(\alpha)}+b_{3}^{(\alpha)}\right]$ \\
Subtraction & $A-B$ & $\tilde{A}-\tilde{B}=\left[a_{1}^{(\alpha)}-b_{3}^{(\alpha)}, a_{3}^{(\alpha)}-b_{1}^{(\alpha)}\right]$ \\
Multiplication & $A \cdot B$ & $\tilde{A} \cdot \tilde{B}=\left[a_{1}^{(\alpha)} \cdot b_{1}^{(\alpha)}, a_{3}^{(\alpha)} \cdot b_{3}^{(\alpha)}\right]$ \\
Division & $A \div B$ & $\tilde{A} \div \tilde{B}=\left[a_{1}^{(\alpha)} \div b_{3}^{(\alpha)}, a_{3}^{(\alpha)} \div b_{1}^{(\alpha)}\right]$, if $0 \notin\left[b_{1}^{(\alpha)}, b_{3}^{(\alpha)}\right]$ \\
\hline
\end{tabular}

been employed to analyze the fuzzy reliability of various industrial systems including butter-oil, paper, and fertilizer manufacturing plants, waste clean up manipulator etc (Komal et al. 2009, 2010; Kumar et al. 2012). It is noticed that FLT gives wide spreads for computed fuzzy reliability parameters of any complex repairable system with numerous components.

Considering the influence of growing event of fuzziness, it may be possible that the decision-maker may suggest some impressive corrections which may improve the system performance. However, it may also be possible that after incorporating suggested corrections, system performance may not improve up to the desired level, because suggestions are inappropriate due to the wide ranges of prediction. To reduce the range of prediction and to make effective decisions, soft computingbased techniques were developed for analyzing the fuzzy reliability of complex repairable systems (Komal et al. 2009, 2010).

The aim of the present work is to analyze the reliability of a robotic system up to a desired degree of accuracy under uncertain environment by reducing the complexity in calculations and utilizing available raw data. The aim is also to reduce the ranges of the prediction for computed reliability indices, so that better decisions may be drawn from the analysis which may help to optimize the performance of the system.

The paper is organized as follows. Section 2 describes the methodology. Robotic system is described together with obtained results in Sect. 3. Sensitivity analysis is also performed in this section followed by concluding remarks in Sect. 4.

\section{Methodology}

The main aim of the paper is to evaluate the performance of a robotic system by utilizing vague, imprecise, and uncertain data. For the reliability analysis of any repairable system, the following assumptions are being used in the literature:

- the failures and repair rates of the components are statistically independent and obey exponential distribution function;

- the product of the failure rate and repair time is small (less than 0.1);

- after repairs, the repaired component is considered as good as new;

- system structure is precisely known.

\section{Existing Fuzzy Lambda-Tau (FLT) technique}

Fuzzy lambda-tau technique developed by Knezevic and Odoom (2001) is a traditional method for analyzing fuzzy reliability of the system. In this methodology, Petrinets $(\mathrm{PN})$ is used for the qualitative modeling and lambdatau method of solution derived in Mishra (1992) is utilized for quantitative modeling. In lambda-tau method, mathematical expressions for failure rate $\left(\lambda_{s}\right)$ and repair time $\left(\tau_{s}\right)$ of the system are formulated in terms of its constituting component's failure rates $\left(\lambda_{i}{ }^{\prime}\right.$ 's) and repair times $\left(\tau_{i}{ }^{\prime} s\right)$. The basic expressions of lambda-tau method are expressed in Table 1 . The various reliability parameters can be evaluated according to Table 2 using fuzzy arithmetic operations given in (Table 3). 
This approach is suitable for small-scale simplified systems. If FLT is implemented for analyzing fuzzy reliability of any complex system with numerous components, then computed fuzzy reliability indices have wide spreads. The reason is the growing event of fuzziness due to the use of $\alpha$-cut interval arithmetic operations in the computations (Chen 1994). Thus, using highly uncertain data and the obtained results, decision-maker cannot suggest any specific and influential managerial strategy to prevent unexpected failures and consequently to improve the industrial system performance. To overcome this problem, a hybridized technique is used in this paper and described in the next subsection.

\section{Hybridized technique}

This technique utilizes fuzzy set theory to quantify uncertainties, fault tree to model the system, and lambda-tau method to formulate the mathematical expressions of system's failure/repair rates and the genetic algorithm is utilized to solve established nonlinear programming problems. The expression of the various reliability parameters of the system is evaluated in terms of component's failure rate and repair time of the system using Tables 1 and 2. The evaluated reliability parameters so obtained are nonlinear as the system has complex structure. The failure and repair data of system's components are exponentially distributed and, therefore, are not precisely known. Quantification of involved uncertainties is done through data fuzzification using triangular fuzzy numbers. The optimization problem (1) is used for finding system fuzzy reliability parameters.

Minimize/maximize:

$$
\begin{aligned}
& \tilde{P}\left(\lambda_{1}, \lambda_{2}, \ldots, \lambda_{n}, \tau_{1}, \tau_{2}, \ldots, \tau_{n}\right) \quad \text { or } \quad \tilde{P}\left(t / \lambda_{1}, \lambda_{2}, \ldots, \lambda_{n}, \tau_{1},\right. \\
& \left.\quad \tau_{2}, \ldots, \tau_{n}\right)
\end{aligned}
$$

Subject to $:=v_{\lambda_{i}}(x) \geq \alpha$,

$$
\begin{aligned}
& v_{\tau_{i}}(x) \geq \alpha \\
& 0 \leq \alpha \leq 1 \\
& i=1,2, \ldots, n
\end{aligned}
$$

Here, $\quad \tilde{P}\left(\lambda_{1}, \lambda_{2}, \ldots, \lambda_{n}, \tau_{1}, \tau_{2}, \ldots, \tau_{n}\right) \quad$ and $\quad \tilde{P}\left(t / \lambda_{1}, \lambda_{2}\right.$, $\left.\ldots, \lambda_{n}, \tau_{1}, \tau_{2}, \ldots, \tau_{n}\right)$ are time-independent (system failure rate, repair time, and MTBF) and time-dependent (system reliability, availability, and ENOF) fuzzy reliability parameters, respectively. The obtained minimum and maximum values of $\tilde{P}$ are denoted by $P_{\min }$ and $P_{\max }$, respectively. The membership function values of $\tilde{P}$ at $P_{\min }$ and $P_{\max }$ are both $\alpha$, that is

$v_{\tilde{P}}\left(P_{\min }\right)=v_{\tilde{P}}\left(P_{\max }\right)=\alpha$.
The optimization problem so obtained is highly nonlinear. Various methods and algorithms have been developed for optimization and have been utilized in various research areas (Tillman et al. 1980; Ravi et al. 1997, 2000; Konak et al. 2006). Genetic algorithms (GAs) is one of the most effective evolutionary algorithms. Genetic algorithms have been applied to the optimization of various reliability problems (Juang et al. 2008; Lapa et al. 2006; Martorell et al. 2005; Konak et al. 2006; Komal et al. 2009, 2010).

Any nonlinear optimization problem without checking the convexity and differentiability of objective functions can be solved effectively using Genetic algorithms (Goldberg 1989; Konak et al. 2006). Therefore, we have selected GAs as a tool to solve the optimization problem (1). In the literature, the variety of GAs are available such as binarycoded GA, real-coded GA, NSGA, etc. Among the many GAs available in the literature, the present study utilizes binary-coded GA to solve above formulated nonlinear optimization problems. In the beginning of the solution process, failure rates $\left(\lambda_{i}{ }^{\prime}\right.$ s) and repair times $\left(\tau_{i}\right.$ 's) of system's components are encoded as the strings of selected bit length $l$, a parameter of GA, that finally constitute a chromosome. For the maximization problem (1), the objective function is considered as the fitness function, while reciprocal of the objective function is considered as the objective function for the minimization problem (1). Roulette wheel selection process is employed for the selecting potentially useful solutions for the recombination. Crossover and mutation are another two important basic operators used in any GA. There are many types of crossover and mutation operators depending upon the type of encoding and also on a problem. In the present study, one-point crossover and random-point mutation operators are employed. Maximum number of generations and change in population fitness value are used to stop the optimization process. The coding of the above developed GA has been done in MATLAB 7.1 environment. Different sets of values of all the parameters of GA are tested and the best set of values is selected for analysis which gives better optimum solution of the problem. After solving above formulated nonlinear optimization problems (1) for each cut-level $\alpha$ using developed binary-coded GA, we have fuzzy reliability indices with reduced spread at each cutlevel $\alpha$.

\section{System description and results}

In the present study, various reliability parameters of a robotic system with a conveyer unit are evaluated. The system consists of two robots and one conveyor unit between them. This system may be utilized as a conveyor 
Fig. 1 Fault tree of robotic system

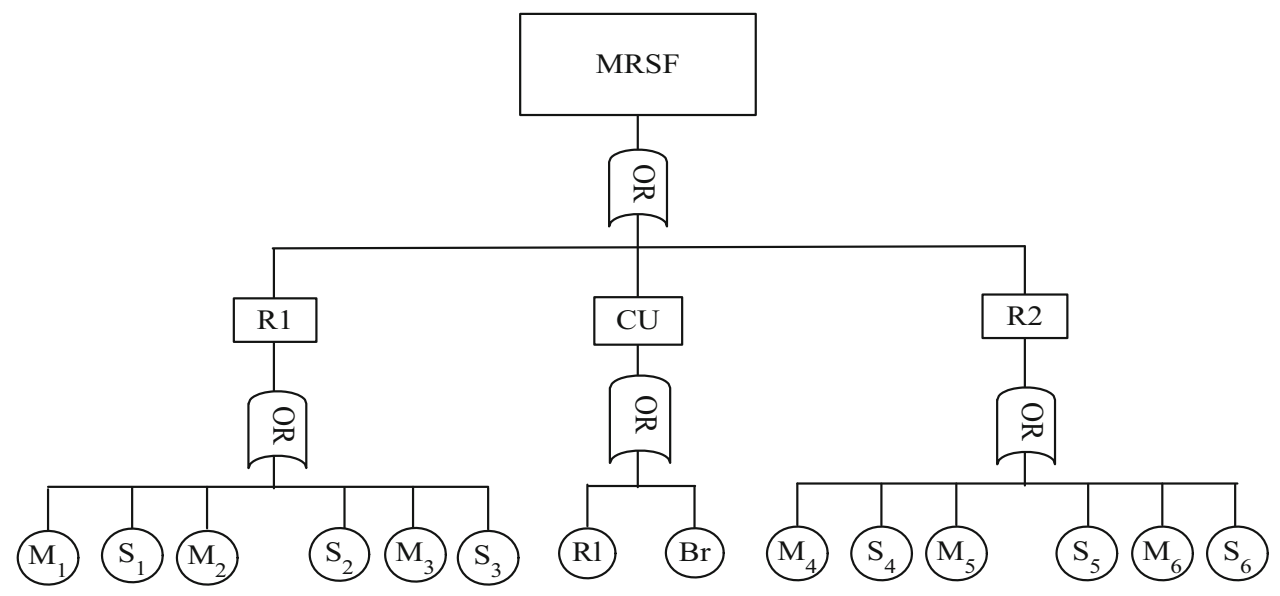

system in industries. There are three joints in each robot. Each joint has one motor $\left(M_{i}, 1 \leq i \leq 6\right)$ and one sensor $\left(S_{i}, 1 \leq i \leq 6\right)$. The conveyor unit has a bearing $(\mathrm{Br})$ and a roller $(\mathrm{Rl})$ as its components. The fault tree model of the robot is depicted in Fig. 1. Minimal cut sets of the system are $\left\{M_{i}, 1 \leq i \leq 6\right\} ;\left\{S_{i}, 1 \leq i \leq 6\right\} ;\{\mathrm{Br}\}$; and $\{\mathrm{Rl}\}$ which are obtained using matrix method (Knezevic and Odoom 2001).

Using Table 1, the expression for the system failure rate $\left(\lambda_{s}\right)$ and repair time $\left(\tau_{s}\right)$ takes the following forms:

$\lambda_{s}=\sum_{i=1}^{14} \lambda_{i}$

Table 4 Failure rates and repair times data for robotic system

\begin{tabular}{lll}
\hline Component & Failure rate $\left(\lambda_{i}\right)\left(\mathrm{h}^{-1}\right)$ & Repair time $\left(\tau_{i}\right)(\mathrm{h})$ \\
\hline Motors $(M, 1 \leq i \leq 6)$ & $1.85 \times 10^{-5}$ & 2.0 \\
Sensors $(S, 7 \leq i \leq 12)$ & $2.35 \times 10^{-5}$ & 2.0 \\
Bearing $(\mathrm{Br}, i=13)$ & $1.55 \times 10^{-5}$ & 1.0 \\
Roller $(\mathrm{R} 1, i=14)$ & $1.50 \times 10^{-5}$ & 2.0 \\
\hline
\end{tabular}

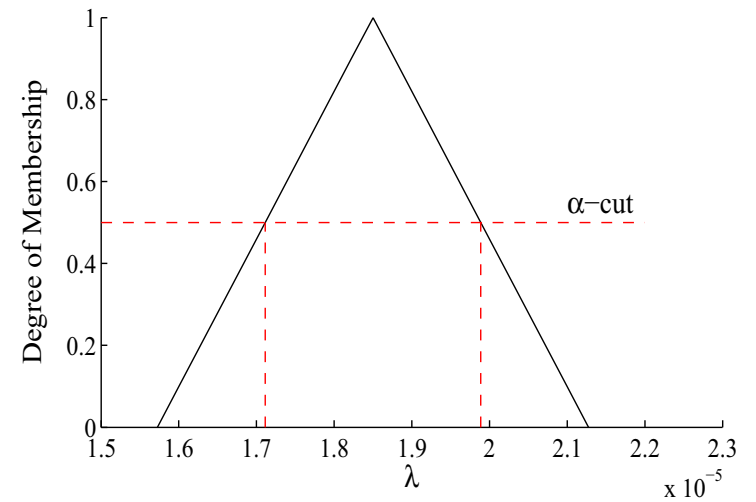

(a) Failure Rate $\tau_{s}=\frac{\sum_{i=1}^{14} \lambda_{i} \tau_{i}}{\lambda_{s}}$

Utilizing these expressions along with expressions given in Table 2, the system reliability parameters are obtained. The failure rate and repair time of the main components of the robotic system following exponential distribution and their values are given in Table 4 (Sharma et al. 2010). Quantification of involved uncertainties in crisp input data is done through data fuzzification using triangular fuzzy numbers with $\pm 15, \pm 25$ and $\pm 50 \%$ spreads. For an example, the input for $\pm 15 \%$ (failure rate and repair time) for the motor is shown in Fig. 2. Using fuzzy input and expressions for reliability parameters, fuzzy reliability parameters of the system have been evaluated using hybridized technique for mission time $t=100(\mathrm{~h})$ to analyze the behavior of the system. For this technique, a nonlinear optimization problem (1) has been formulated. To solve the established optimization problem (1), the parameters of GA are taken as follows:

Population size $=120$

Probability of crossover $(P c)=0.85$

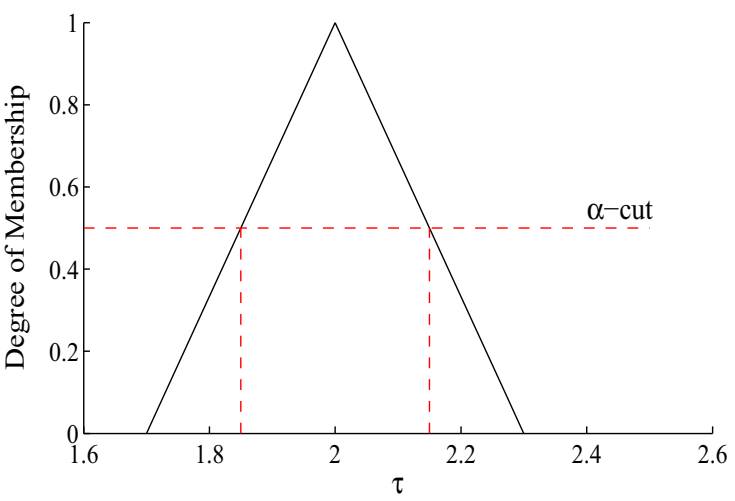

(b) Repair Time

Fig. 2 Fuzzy input for motor 


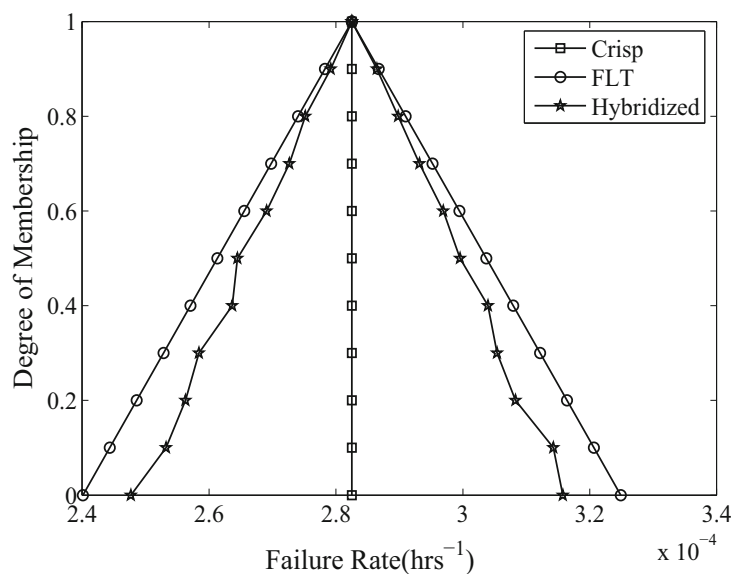

(a)

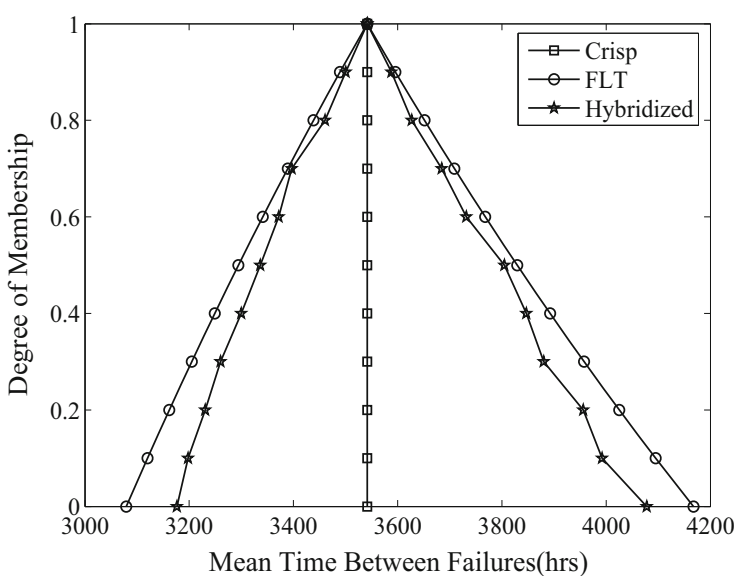

(c)

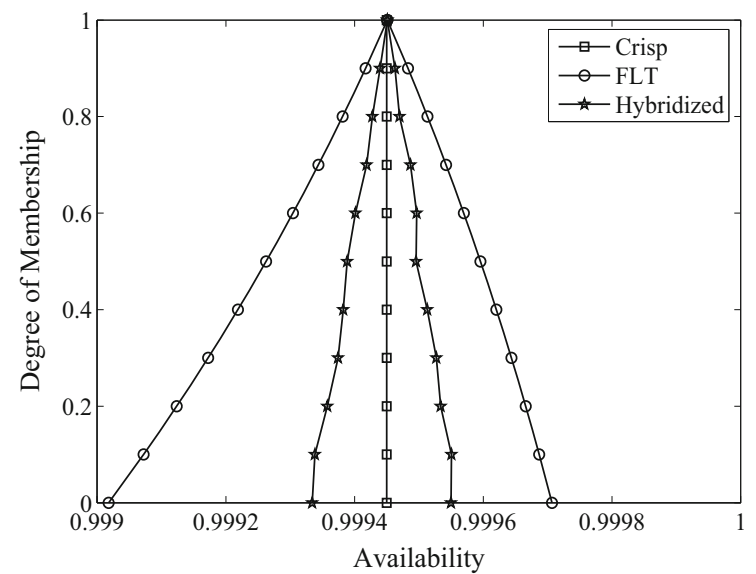

(e)

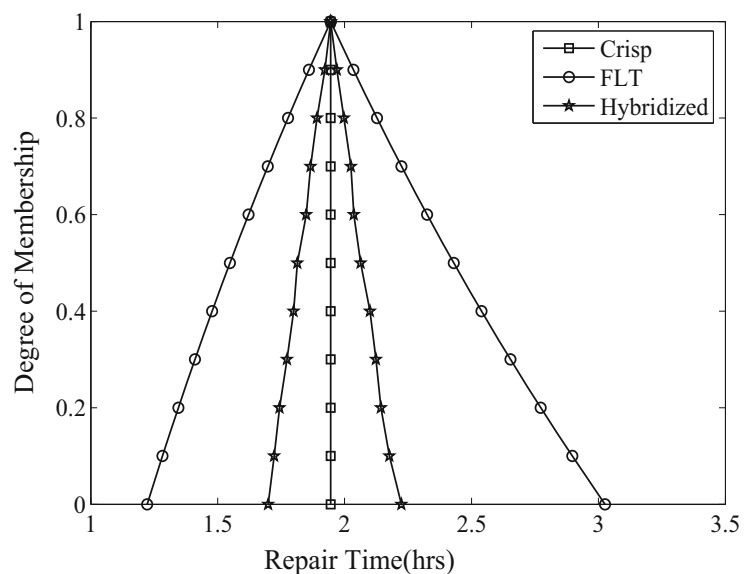

(b)

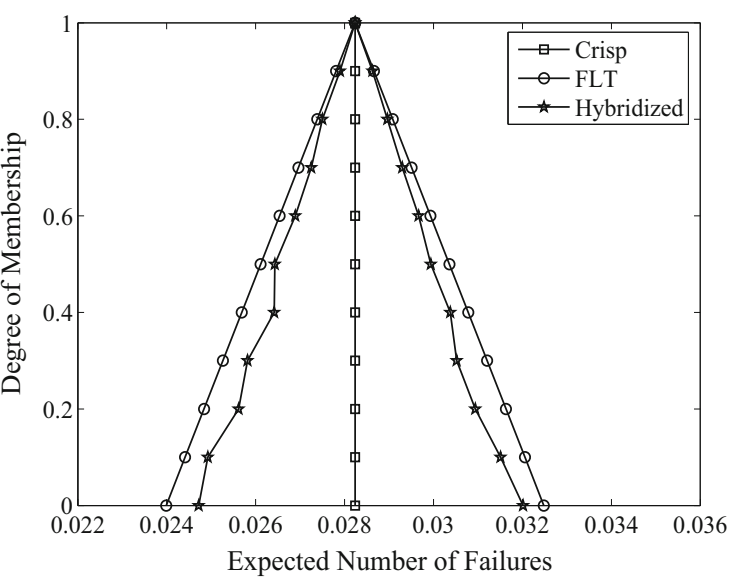

(d)

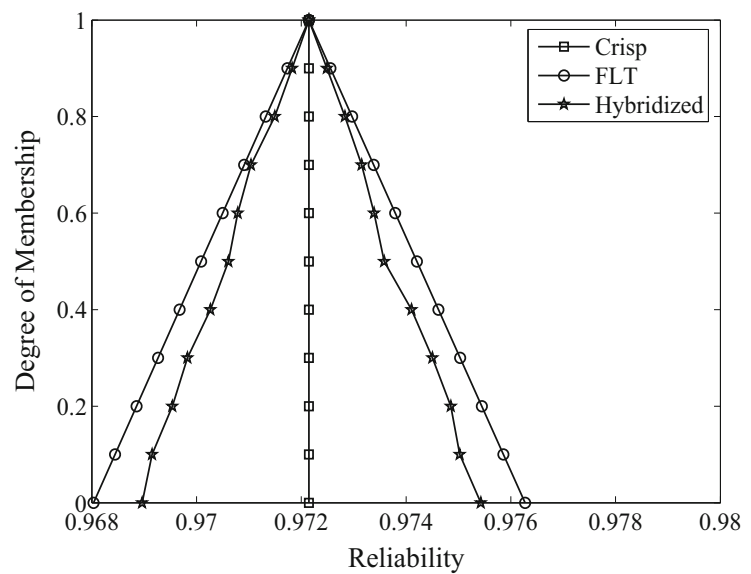

(f)

Fig. 3 Fuzzy reliability indices plots for robotic system with $\pm 15 \%$ uncertainty

Probability of mutation $(P m)=0.005$

Number of iterations $=500$

Number of runs $=20$.

The fuzzy reliability parameters of the system under consideration have also been evaluated using the existing FLT (Sharma et al. 2010). The computed results have been plotted in Fig. 3 for $\pm 15 \%$ uncertainty level. Results clearly indicate that the used hybridized technique provides better fitted results in comparison to FLT technique. Thus, the prediction range for any reliability parameter at each cut-level $\alpha$ is decreased which will be beneficial for making sound decisions. The crisp and defuzzified values using 
Table 5 Crisp and defuzzified values of reliability parameters of the system

\begin{tabular}{lllll}
\hline Reliability parameters & Crisp & \multicolumn{2}{l}{ Defuzzified values at (spread) } \\
\cline { 3 - 5 } & & $\pm 15 \%$ & $\pm 25 \%$ & $\pm 50 \%$ \\
\hline Failure rate $\left(\times 10^{-4} \mathrm{~h}^{-1}\right)$ & 2.825000 & FLT: 2.825013 & 2.835217 & 3.152798 \\
& & Hybridized:2.827082 & 2.841784 & 2.866221 \\
Repair time (h) & \multirow{2}{*}{1.945133} & 2.034763 & 2.203569 & 3.204719 \\
& & 1.947378 & 1.948024 & 1.944006 \\
MTBF (h) & \multirow{2}{*}{3541.768} & 3522.729 & 3212.815 & 2998.759 \\
& & 3570.878 & 3519.429 & 3489.429 \\
ENOF & \multirow{2}{*}{0.028235} & 0.028315 & 0.029719 & 0.029915 \\
& & 0.028254 & 0.028402 & 0.028646 \\
Availability & \multirow{2}{*}{0.999450} & 0.998406 & 0.988321 & 0.987799 \\
Reliability & & 0.999447 & 0.999446 & 0.999443 \\
& \multirow{2}{*}{0.972145} & 0.971501 & 0.968925 & 0.942509 \\
& & 0.972120 & 0.971982 & 0.971745 \\
\hline
\end{tabular}

first combination, the chosen values of reliability, failure rate, and availability are $0.9722,2.825 \times 10^{-4}$, and 0.9994 , respectively. The calculated ranges of MTBF are 3072.808- 4160.350, and 3117.559-4037.021 for FLT technique and hybridized technique, respectively. One can observe that for this combination, the prediction range of MTBF is reduced by approximately $16 \%$ from FLT technique when hybridized technique is utilized. From this observation, we can conclude that if system analyst uses results based on hybridized technique, then he may have less range of prediction, and finally, he will lead to more sound decisions. Similar behavior has also been noticed for rest other combinations. Based on the above observations, the system analyst can analyze the critical behavior of the system and he can prepare a suitable plan for maintenance.

\section{Conclusion}

In this paper, a hybridized technique is used for the performance analysis of a robotic system. Various reliability parameters such as system failure rate, repair time, MTBF, ENOF, availability, and reliability are calculated. The calculated reliability parameters are in the form of fuzzy membership functions. Depending upon the confidence level ' $\alpha$ ', the analyst can predict the behavior of the system(s). The defuzzified values of reliability indices for different level of uncertainties with their crisp values have been computed and tabulated. It can be concluded that the system analyst should perform the system maintenance on the basis of defuzzified MTBF rather than the crisp value. Similarly, it can be realized that with increasing repair time, the reduced value of reliabillity/availability is more conservative than that of the crisp value. Based on the 


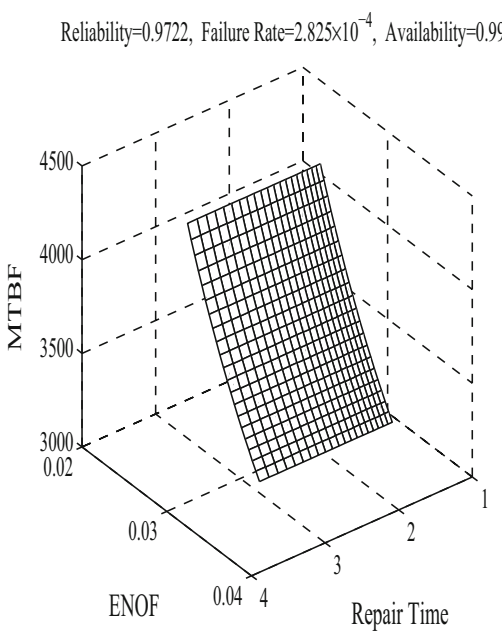

(a)

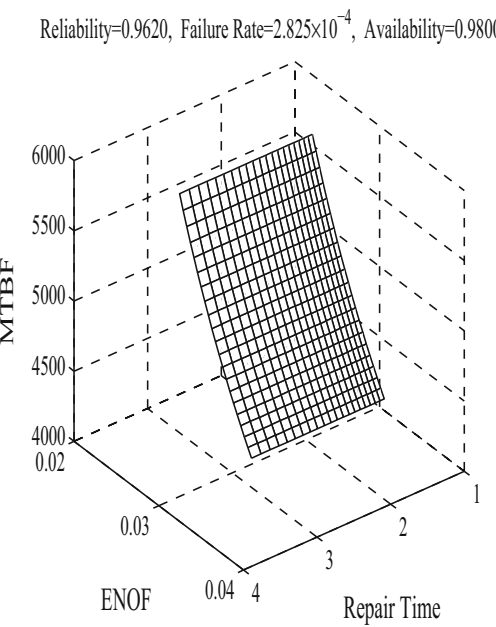

(d)

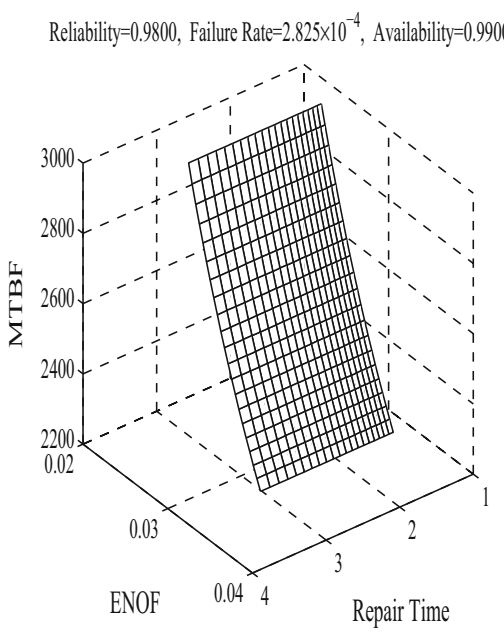

(g)
Reliability $=0.9722$, Falure Rate=2.82010 $0^{-4}$, Availability $=0.9994$

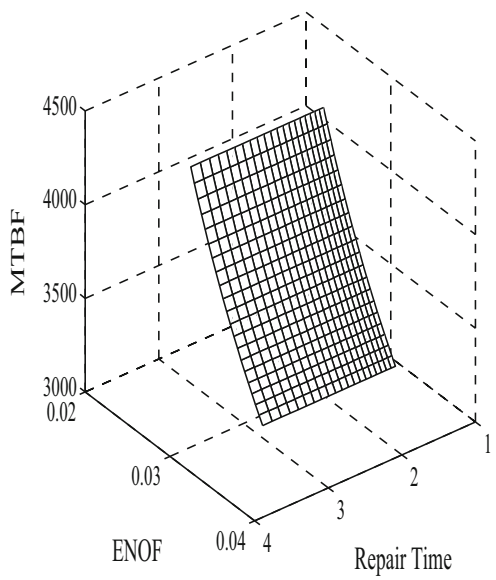

(b)

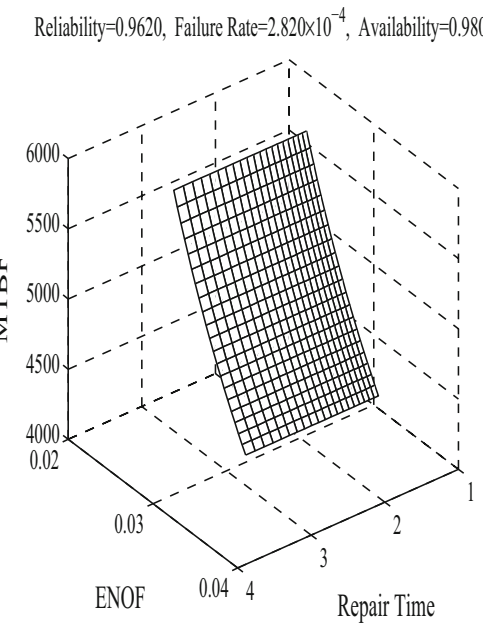

(e)

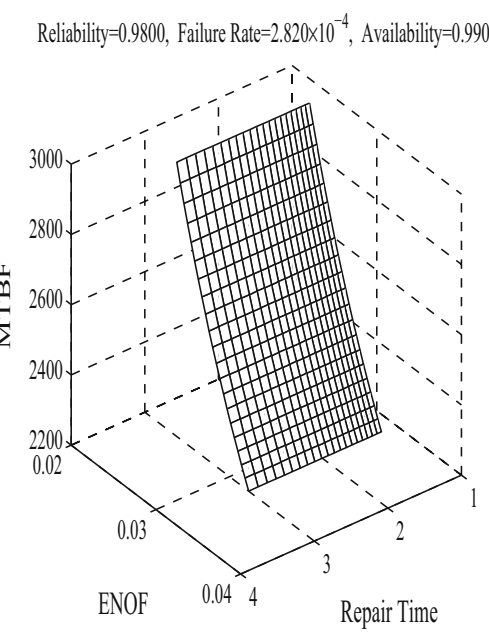

(h)

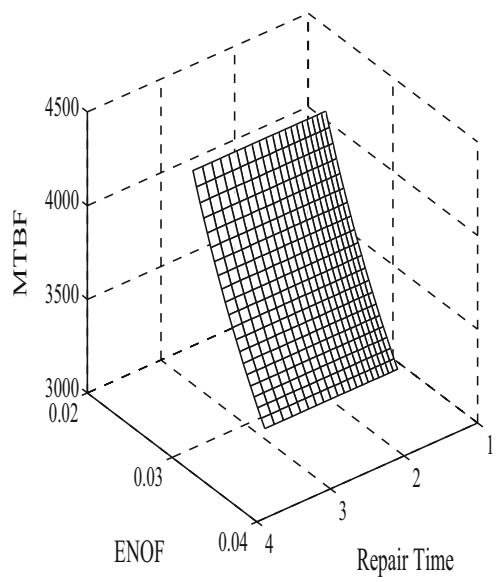

(c)

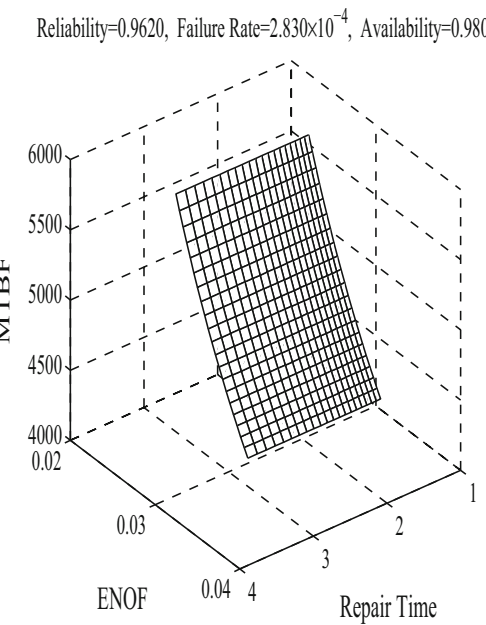

(f)

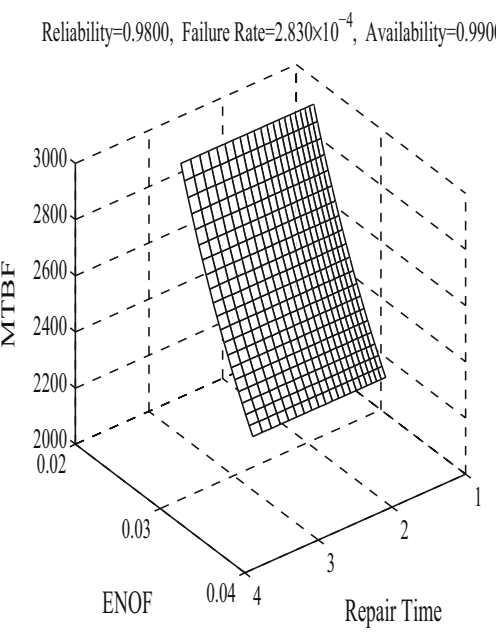

(i)

Fig. 4 Behavior analysis plots for robotic system using FLT technique results 


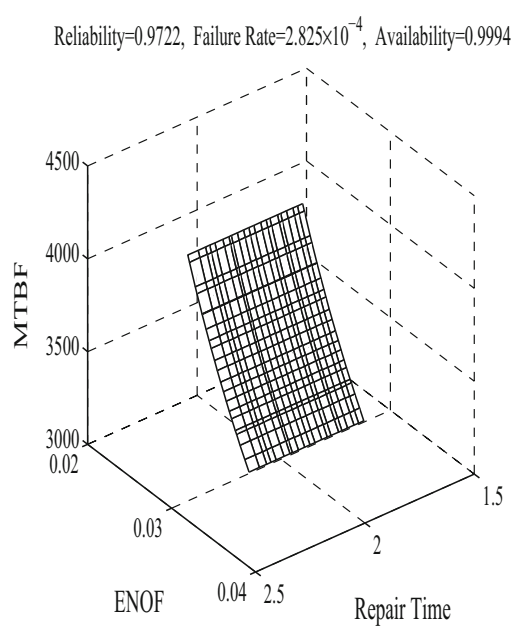

(a)

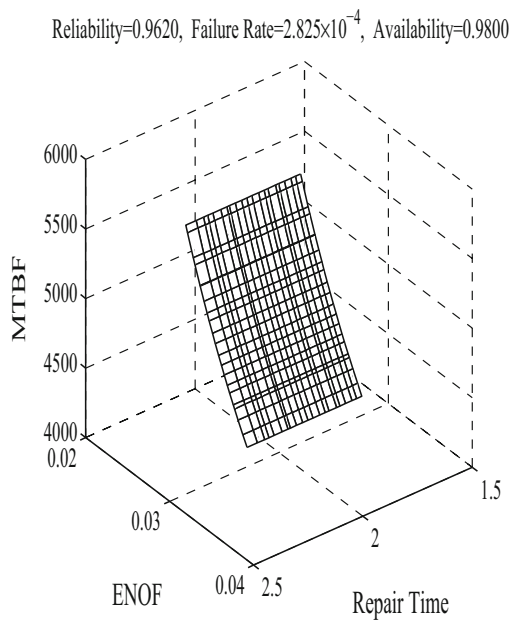

(d)

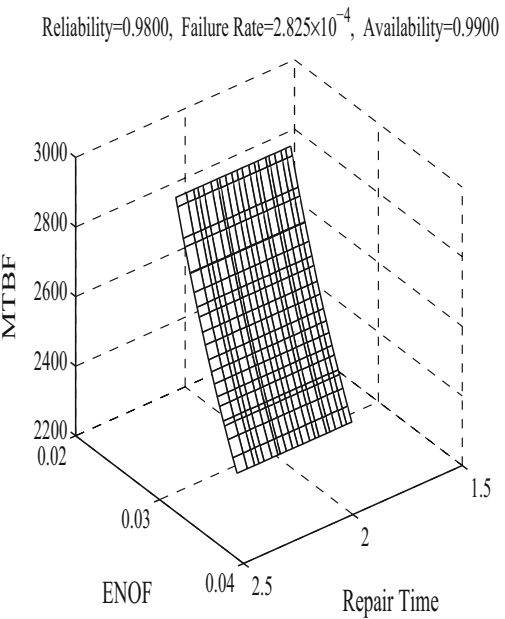

(g)

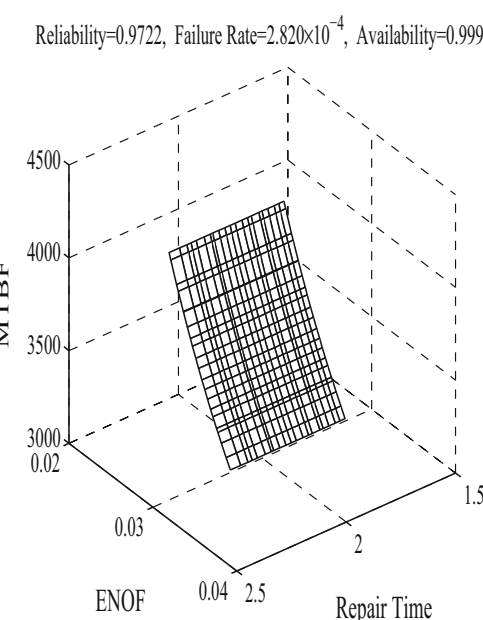

(b)

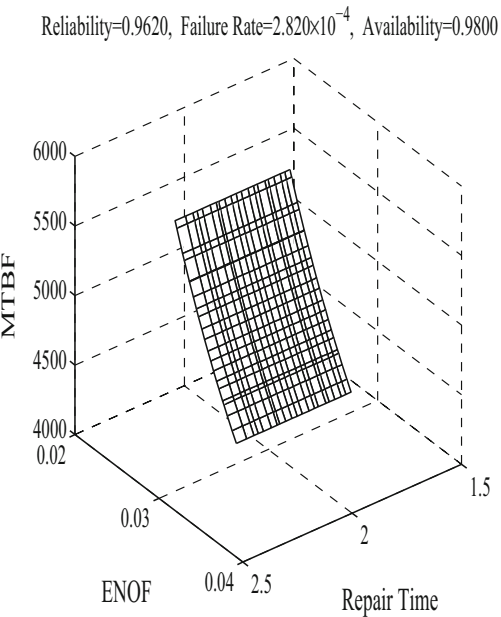

(e)

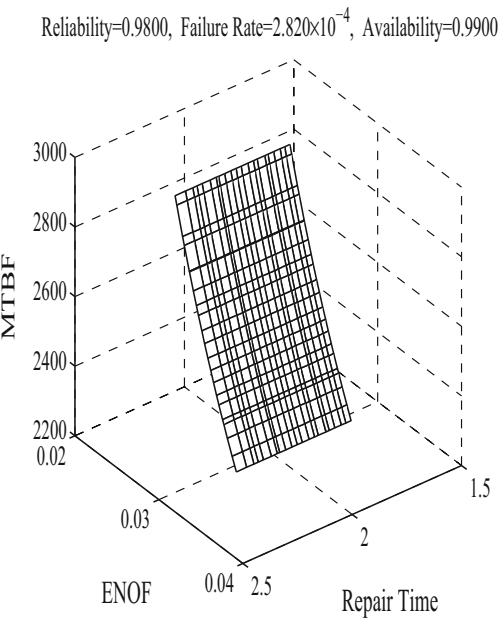

(h)

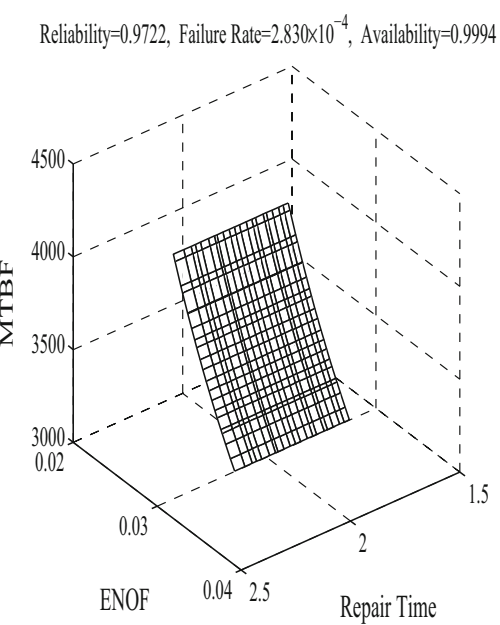

(c)

Reliability $=0.9620$, Failure Rate $=2.830 \times 10^{-4}$, Availability $=0.9800$

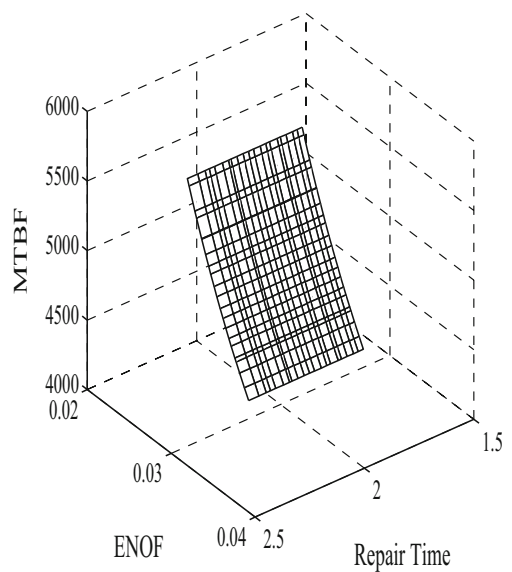

(f)

Reliability $=0.9800$, Failure Rate $=2.830 \times 10^{-4}$, Availability $=0.9900$

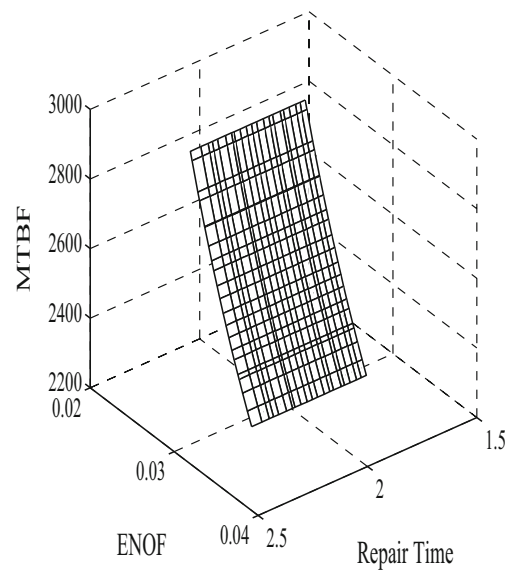

(i)

Fig. 5 Behavior analysis plots for robotic system using hybridized technique results 
Table 6 Change in MTBF for various combinations of reliability indices for the system

\begin{tabular}{|c|c|c|c|}
\hline \multirow[t]{2}{*}{$\begin{array}{l}\text { S. } \\
\text { No. }\end{array}$} & \multirow[t]{2}{*}{$\begin{array}{l}\text { [Reliability, failure rate, } \\
\text { availability] }\end{array}$} & \multicolumn{2}{|c|}{$\begin{array}{l}\text { Mean time between } \\
\text { failures }\end{array}$} \\
\hline & & FLT & Hybridized \\
\hline \multirow[t]{2}{*}{1.} & {$\left[0.9722,2.825 \times 10^{-4}, 0.9994\right]$} & $\begin{array}{l}\text { Min: } \\
3072.808\end{array}$ & 3117.559 \\
\hline & & $\begin{array}{l}\text { Max: } \\
\quad 4160.350\end{array}$ & 4037.021 \\
\hline \multirow[t]{2}{*}{2.} & {$\left[0.9722,2.820 \times 10^{-4}, 0.9994\right]$} & 3078.257 & 3123.087 \\
\hline & & 4167.727 & 4044.179 \\
\hline \multirow[t]{2}{*}{3.} & {$\left[0.9722,2.830 \times 10^{-4}, 0.9994\right]$} & 3067.380 & 3112.051 \\
\hline & & 000 & 4.029 .889 \\
\hline \multirow[t]{2}{*}{4.} & {$\left[0.9620,2.825 \times 10^{-4}, 0.9800\right]$} & 4223.048 & 5719.129 \\
\hline & & 4284.836 & 5548.970 \\
\hline \multirow[t]{2}{*}{5.} & {$\left[0.9620,2.820 \times 10^{-4}, 0.9800\right]$} & 4230.535 & 5729.265 \\
\hline & & 4292.432 & 5558.806 \\
\hline \multirow[t]{2}{*}{6.} & {$\left[0.9620,2.830 \times 10^{-4}, 0.9800\right]$} & 4215.589 & 5709.029 \\
\hline & & 4277.268 & 5539.169 \\
\hline \multirow[t]{2}{*}{7.} & {$\left[0.9800,2.825 \times 10^{-4}, 0.9900\right]$} & 2202.234 & 2982.378 \\
\hline & & 2234.449 & 2893.658 \\
\hline \multirow[t]{2}{*}{8.} & {$\left[0.9800,2.820 \times 10^{-4}, 0.9900\right]$} & 2206.138 & 2987.664 \\
\hline & & 2238.410 & 2898.788 \\
\hline \multirow[t]{2}{*}{9.} & {$\left[0.9800,2.830 \times 10^{-4}, 0.9900\right]$} & 2198.344 & 2977.111 \\
\hline & & 2230.502 & 2888.548 \\
\hline
\end{tabular}

above observations, the system analyst can analyze the critical behavior of the system and he can prepare a suitable plan for effective maintenance.

We can also conclude that hybridized technique gives reduced range of reliability indices at any cut level. Using these results, the prediction of system behavior can be observed more confidently. This will help the management in reassignment of the resources, taking maintenance decisions effectively, getting more availability of the system, and, therefore, exaggerating the productivity of the system.

Open Access This article is distributed under the terms of the Creative Commons Attribution 4.0 International License (http://crea tivecommons.org/licenses/by/4.0/), which permits unrestricted use, distribution, and reproduction in any medium, provided you give appropriate credit to the original author(s) and the source, provide a link to the Creative Commons license, and indicate if changes were made.

\section{References}

Bai X, Asgarpoor S (1996) Fuzzy-based approaches to substation reliability evaluation. Electr Power Syst Res 69(2-3):197-204

Cai KY (1996) System failure engineering and fuzzy methodology: an introductory overview. Fuzzy Sets Syst 83:113-133
Carlson J, Murphy RR (2003) Reliability analysis of mobile robots. Proc IEEE Annu Reliab Maintainab Symp 1:274-281

Carreras C, Walker ID (2000) On interval methods applied to robot reliability quantification. Reliab Eng Syst Saf 70(3):291-303

Carreras C, Walker ID, Taladriz ON, Cavallaro JR (1999) Robot reliability estimation using interval methods. In: Proceedings of the International workshop on applications of interval analysis to systems and control, pp 371-385

Chen SM (1994) Fuzzy system reliability analysis using fuzzy number arithmetic operations. Fuzzy SetsSyst 64(1):31-38

Das K (2008) A comparative study of exponential distribution vs weibull distribution in machine reliability analysis in a cms design. Comput Ind Eng 54(1):12-33

Dhillon BS, Yang N (1996) Availability analysis of a robot with safety system. Microelectron Reliab 36(2):169-177

Goldberg DE (1989) Genetic algorithm in search, optimization and machine learning. Addison-Wesley, Boston

Juang YS, Lin SS, Kao HP (2008) A knowledge management system for series-parallel availability optimization and design. Expert Syst Appl 34:181-193

Khodabandehloo K (1996) Analysis of robot systems using fault and event trees: case studies. Reliab Eng Syst Saf 53(3):247-264

Knezevic J, Odoom ER (2001) Reliability modeling of repairable systems using petri nets and fuzzy lambda-tau methodology. Reliab Eng Syst Saf 73(1):1-17

Komal, Sharma SP, Kumar D (2009) Stochastic behavior analysis of the press unit in a paper mill using GABLT technique. Int J Intell Comput Cybern 2(3):574-593

Komal, Sharma SP, Kumar D (2010) RAM analysis of repairable industrial systems utilizing uncertain data. Appl Soft Comput 10:1208-1221

Konak A, Coit DM, Smith A (2006) Multi-objective optimization using genetic algorithms: a tutorial. Reliab Eng Syst Saf 91(9):992-1007

Korayem MH, Iravani A (2008) Improvement of 3P and 6R mechanical robots reliability and quality applying FMEA and QFD approaches. Robot Comput Integr Manuf 24(3):472-487

Kumar N, Borm JH, Kumar A (2012) Reliability analysis of waste clean-up manipulator using genetic algorithms and fuzzy methodology. Comput Oper Res 39(2):310-319

Lapa CM, Pereira CM, Barros MD (2006) A model for preventive maintenance planning by genetic algorithms based on cost and reliability. Reliab Eng Syst Saf 91:233-240

Leuschen ML, Walker ID, Cavallaro JR (1998) Robot reliability through fuzzy Markov models. In: Proceedings of the IEEE annual reliability and maintainability symposium, pp 209-214

Leuschen ML, Walker ID, Cavallaro JR (2001) Evaluating the reliability of prototype degradable systems. Reliab Eng Syst Saf 72(1):9-20

Martorell S, Villanueva JF, Carlos S, Nebot Y, Sanchez A, Pitarch JL, Serradell V (2005) RAMS +C informed decision-making with application to multi-objective optimization of technical specifications and maintenance using genetic algorithms. Reliab Eng Syst Saf 87(1):65-75

Mishra KB (1992) Reliability analysis and prediction: a methodology oriented treatment. Elsevier, Amsterdam

Ravi V, Murty BS, Reddy PJ (1997) Nonequilibrium simulated annealing-algorithm applied to reliability optimization of complex systems. IEEE Trans Reliab 46(2):233-239

Ravi V, Reddy PJ, Zimmermann HJ (2000) Fuzzy global optimization of complex system reliability. IEEE Trans Fuzzy Syst $8(3): 241-248$

Sharma SP, Sukavanam N, Kumar N, Kumar A (2008) Performance analysis of a complex robotic system using fault tree and fuzzy methodology. In: Proceedings of NSC08, Electrical Engineering Department, IIT Roorkee, Roorkee, pp 874-878 
Sharma SP, Sukavanam N, Kumar N, Kumar A (2010) Reliability analysis of complex robotic system using petri nets and fuzzy lambda-tau methodology. Eng Comput 27(3):354-364

Sharma SP, Kumar D, Kumar A (2012) Reliability analysis of complex multi-robotic system using ga and fuzzy methodology. Appl Soft Comput 12(1):405-415

Stancliff SB, Dolan JM, Trebi-Ollenu A (2006) Mission reliability estimation for repairable robot teams. Int $\mathrm{J}$ Adv Rob Syst $3(2): 155-164$
Tillman FA, Hwang CL, Kuo W (1980) Optim Syst Reliab. Marcel Dekker, New York

Walker I, Cavallero J (1996a) Failure mode analysis for a hazardous waste clean-up manipulator. Reliab Eng Syst Saf 53(3):277-290

Walker ID, Cavallaro JR (1996b) The use of fault trees for the design of robots for hazardous environments. In: Proceedings of the IEEE annual reliability and maintainability symposium, pp 229-235 